\title{
GENDER BIAS IN THE 1996 OLYMPIC GAMES
}

\section{A Comparative Analysis}

\author{
Catriona T. Higgs \\ Karen H. Weiller \\ Scott B. Martin
}

This study examined the televised coverage of the 1996 Summer Olympic Games in Atlanta to determine the amount of coverage time, quality of coverage devoted to men's and women's same sport activities, and to compare this coverage with that of the 1992 Summer Olympic Games. Of the more than 150 hours of NBC televised coverage, a total of 60 hours was then randomly selected as an appropriate sample. A content analysis was then performed on those segments that featured same-sport activities for men and women. This included quantitative (e.g., running time, length of segments, number of slow motion replays, and use of onscreen statistics) and qualitative (e.g., the narrative of the commentators) analyses. Although the findings suggest there have been notable improvements in the way female athletes were presented in the 1996 Olympic Games as compared to the 1992 Olympic Games, there are still many disparities in the coverage of women's sports, especially those that traditionally appeal to the media audience.

Keywords: gender bias; women's sports; Olympic Games

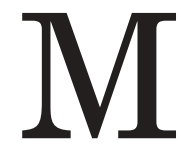

arket forces are largely responsible for the underrepresentation of women's sports by television or, for that matter, in all aspects of the communications media (Hilliard, 1984). Where women are covered, the media has largely focused attention on those sports that are traditionally viewed as conveying a feminine image (e.g., gymnastics and figure skating) and enhancing existing societal norms (Shifflett \& Revelle, 1994). Researchers suggest that sports media influences how people view participation in sports. By emphasizing certain facets of female participation in sports while ignoring others, the sports media effectively shapes the public agenda and influences the public's judgment about the world of sport, and the athletes who are a part of that competition (Coakley, 1998). NBC experienced an enormous ratings success (Coakley, 1998) and were afforded extraordinary ratings, the best since 1976. Part of the ratings success can be attributed to the United States' hosting of these games, yet as noted by Remnich (1996) and Coakley (1998), NBC provided viewers with a reality

Journal of Sport \& Social Issues, Volume 27, No. 1, February 2003, pp. 52-64 DOI: $10.1177 / 0193732502239585$

(C) 2003 Sage Publications 
that was designed to "bring a tear to the eye and billions to the coffers" (Remnich, 1996, p. 26). Furthermore, Remnich (1996) suggested NBC framed events, specifically withholding information, therefore deliberately shaping their broadcasts to appeal to a female audience.

Previous studies of the media coverage of women have demonstrated a significant difference in the way that male and female athletes are covered by televised media (Duncan, Messner, Williams, \& Jensen, 1990; Higgs \& Weiller, 1994; Kahn \& Goldenberg, 1991; Theberge, 1991). Duncan et al. (1990) have suggested that the Olympic Games is an event that attempts to target female spectators through the coverage of feminine sports in an attempt to attract female viewership. Daddario (1997) noted the focus by the media on "women's spectator sports" in the first week of NBC's 1992 Olympic coverage. In fact, NBC's highest rating for the 2-week period of coverage was for the night of a gymnastics telecast (Daddario, 1997). Daddario (1997) further emphasized NBC's programming strategy of pretaping events and packaging them for a specific type of storytelling approach. This approach served to personalize the lives of the athletes, both male and female, to build an emotional identification with the athletes. Daddario described this as a "feminine narrative form" (p. 107), similar in nature to that used in television soap operas to draw audiences into the focus of the character and plot. The concept of narrative has been used persuasively by televised media to lure viewers into maintaining interest in a desire for further viewing (Harris \& Hills, 1993). The intent of this type of programming in the 1996 Olympic Games was to "emphasize the human drama of the Summer Games ... to reach their target audience, in which the 25 to 54 year old female figured prominently" (Daddario, 1997, p. 112).

A previous study by Higgs and Weiller (1994) demonstrated that although women were given greater coverage in individual sports during the 1992 Olympic Games, that coverage was divided into shorter and more heavily edited segments. In addition, commentaries centered on gender marking, biased and ambivalent reporting, and focused on personalities as opposed to athletic abilities when covering women's sports.

The phenomenal success of the American women athletes in the 1996 Olympic Games clearly demonstrated to the American public the quality, depth, and progress of women's sports in America since the advent of Title IX (Kane \& Parks, 1992). The question that remains is, With such a heightened focus on women's sports, and on women athletes, was the television coverage of the 1996 Games less stereotyped and gender hierarchical than the coverage in 1992 ?

PURPOSE

The purpose of this study was to examine televised coverage of the 1996 Summer Olympic Games in Atlanta to determine the amount of coverage time, quality of coverage devoted to men's and women's same sport activities, and to compare this coverage with that of the 1992 Summer Olympic Games. 
NBC televised more than 150 hours of Olympic coverage. All coverage was taped and a content analysis was conducted on only those segments that featured same-sport activities for men and women. A total of 60 hours was then randomly selected as an appropriate sample from the total coverage. A content analysis was then performed on those segments that featured samesport activities for men and women. Randomness was assured by selecting time segments at various times in the day/evening coverage. Quantitative analysis focused on the amount of running time devoted to male and female sports, length of segments, number of slow-motion replays used, and the use of onscreen statistics. Qualitative analysis focused on one particular characteristic, the narrative, by examining adjectives used by the commentators to describe male and female athletes, and the themes stressed by commentators in the course of weaving narratives about the events.

\section{RESULTS}

Of the total 60 hours of taped material, 30 hours and 28 minutes was devoted to same-sport activities. Same-sport events analyzed were the team and individual sports of basketball, volleyball, gymnastics, swimming and diving, track and field, and minor sports of cycling, tennis, kayaking, rowing, and soccer. Compared with our previous study (Higgs \& Weiller, 1994) results demonstrated that women were afforded more televised media coverage in the 1996 Olympics than men in same-sport activities. A comparison between the quantitative time totals of same-sport competition from the 1992 and 1996 Olympic Games revealed that women's sport coverage increased in 6 out of the 11 sports analyzed, whereas male sport coverage declined in 4 out of the 11 sports analyzed. This is a notable result in comparison with previous studies, which have demonstrated that women are usually covered less and for shorter time periods than men (Higgs \& Weiller 1994).

In the present study, total and segment broadcast times devoted to men's and women's basketball, gymnastics, track and field, volleyball, swimming, diving, cycling, tennis, kayaking, rowing, and soccer were examined. Results indicated that time coverage totals for men's track and field was the most televised competition, whereas men's volleyball was the least. (see Table 1).

Most notably, coverage for women increased in team sports of basketball (26\%) and volleyball (69\%), whereas these same sports saw a decrease in time allotted for men. Other sports analyzed in both 1992 and 1996 remained fairly comparable. Time coverage totals for women indicate that gymnastics was the most televised competition, and tennis was the least televised competition. 
TABLE 1

Quantitative Time Totals of Same Sport Competition

From the 1992 and 1996 Summer Olympic Games

\begin{tabular}{lccrrrrr}
\hline \hline & \multicolumn{3}{c}{1992} & & \multicolumn{3}{c}{1996} \\
\cline { 2 - 4 } \cline { 6 - 7 } Sport & $\begin{array}{c}\text { Male } \\
\%\end{array}$ & $\begin{array}{c}\text { Female } \\
\%\end{array}$ & $\begin{array}{c}\text { Total } \\
\text { Time }\end{array}$ & $\begin{array}{c}\text { Male } \\
\%\end{array}$ & $\begin{array}{c}\text { Female } \\
\%\end{array}$ & $\begin{array}{c}\text { Total } \\
\text { Time }\end{array}$ \\
\hline Basketball & 74 & 26 & $18: 23$ & & 48 & 52 & $2: 23$ \\
Volleyball & 75 & 25 & $3: 05$ & & 6 & 94 & $2: 48$ \\
Gymnastics & 16 & 84 & $5: 48$ & & 26 & 74 & $9: 55$ \\
Swimming & 48 & 52 & $3: 35$ & & 43 & 57 & $6: 00$ \\
Diving & 44 & 56 & $2: 11$ & & 26 & 74 & $3: 27$ \\
Track \& Field & 63 & 37 & $9: 10$ & & 74 & 26 & $4: 48$ \\
Cycling & 40 & 60 & $: 52$ & & 0 & 100 & $: 22$ \\
Tennis & 33 & 67 & $: 18$ & & 93 & 7 & $: 36$ \\
Kayaking & 81 & 19 & $: 27$ & & 86 & 14 & $1: 48$ \\
Rowing & 33 & 67 & $: 12$ & & 0 & $: 00$ \\
Soccer & $*$ & $*$ & $*$ & 77 & 23 & $: 21$ \\
& & & & & &
\end{tabular}

NOTE: In 1992, women's soccer was not a medal sport. Men's soccer was a medal sport but was not analyzed by Higgs \& Weiller, 1994.

\section{BASKETBALL}

\section{GENDER DIFFERENCES}

Denial of power, which was a central theme in the coverage of women's basketball in the 1992 Olympic Games, was far less blatant in the 1996 televised coverage. Slow-motion replays, gender marking, and commentators' use of adjective differentials were found to be fairly balanced. Although slow-motion replays were shown more often in the men's games (four per game) than in the women's games (three per game), the disparity was not as great as in the 1992 Olympics where the intense focus on the "dream team" precipitated far more coverage and interest in the men's competition. Although gender marking was evident throughout the coverage, with phrases such as "U.S. Women's team," the use of the word girl was minimal (3 X total).

\section{Strength/Weakness Descriptors}

Commentators' use of adjectives to describe the strengths and weaknesses of men and women were fairly similar. In the 1992 coverage, the words aggressive and powerful to describe the male athletes were used numerous times (185) versus only 68 times in the women's competition. In the coverage of the 1996 Olympic basketball competition, a total of 52 strength descriptors were used to describe the male players versus 47 for the 
women. The ambivalence that was used in the 1992 coverage to describe the women's competition was not as evident. Women players were more often described in positive terms as having plenty of game and grit, being tough, and showing perfect execution in scoring a point.

\section{Narrative}

The emotional narrative that had accompanied the "run for gold" by the 1992 dream team was replaced in the 1996 coverage with a focus by the commentators on the success of the women's team prior to the Olympic competition. The U.S. women's basketball team had come into the competition unbeaten for a period of 2 years and the male commentators mentioned this fact numerous times (14) in their commentary. Similar statements used to describe the dream team of 1992 were evidenced in the narrative of the 1996 women's competition. In 1992, the "dream team rolled over Croatia," in 1996 the women "rolled past Cuba." It is interesting that comparisons were made in the men's games to some of the U.S. women players; a situation that was largely reversed in the 1992 coverage. "Mini" narratives were used to enhance the drama of the competition, allowing viewers to identify with the athletes on a more personal level. Interviews with Karl Malone and Reggie Miller highlighted the extraordinary aspects of the athletes' lives, their successes in the National Basketball Association (NBA) and their hopes and dreams of an Olympic medal. Through such narrative devices, Daddario (1997) comments "mediated sports invite the predominantly male audience to identify with athletes" (p. 166). Although no personal interviews were conducted with the women players during the time frame analyzed, commentators discussed aspects of the women's lives; including colleges attended, degrees earned, playing level (professional/semi-professional), and successes at the collegiate level (i.e., National championships). The lack of emphasis on the feminine form and their personal lives was a sharp deviation from coverage of the 1992 Olympic Games, where there was a great deal of focus on gender stereotypic behaviors and characteristics. The marginalization of women's sports, as evidenced in so many previous studies of media coverage was not as evident in NBC's coverage of the 1996 Women's Olympic Basketball competition.

\section{VOLLEYBALL}

As with basketball, depictions of power were fairly evenly dispersed between the men's and women's competition. Again, this is in sharp contrast to the coverage of the 1992 Olympic volleyball competitions.

\section{Gender Differentials}

More slow-motion replays were used in the women's games than in the men's games (24/11). In addition, men's first names were used more often than women's first names (8/1). Hierarchy of naming (Duncan et al., 1990) 
was not evidenced in this portion of the analysis. Commentators used only men's surnames $40.6 \%$ of the time compared with $46.3 \%$ of the time for women. In general, first and last names were used equally to describe the athletes (55.2\% men; $53.3 \%$ women).

\section{Strength/Weakness Descriptors}

Strength descriptors in both events outweighed weakness descriptors (men 34/4; women 25/5), a result that mirrors that of the coverage in 1992.

\section{Narratives}

Narratives in the men's and women's games in the 1992 Olympics revealed a strong distinction in presentation of male dominance and strength (Higgs \& Weiller, 1994), whereas narratives of the 1996 competition were far less distinctive. Comments such as "two of the best middle blockers in the game" and "they have raised the level of this game substantially" are examples of the nature of the narrative. The focus on the men's games was equally interesting. The men's squad was described as "emotional" and "frustrated," "struggling for recognition and respect." Audiences were not left wondering as they were in 1992 about the viability of the women's team events as legitimate competition. Rather, women's events were presented in such a way that no systematic discrimination between the men's and women's coverage was discernible. This finding is in distinct contrast to previous studies (Duncan et al., 1990; Higgs \& Weiller, 1994), which have suggested that coverage of women's team sports have traditionally been trivialized.

\section{GYMNASTICS}

The major theme that seems to emerge from an analysis of the men's and women's gymnastics coverage of the 1996 Olympic Games is that the traditional trivialization of women's athletic performance was still strongly represented in the coverage of this event.

\section{Gender Differentials}

First-name descriptors were used frequently in the women's events. Female athletes were referred to by their first name 177 times versus only 16 times for the male athletes. Although, the coverage of the men's gymnastic events was still less in total time than that for the women, these figures still suggest a disparity in this particular area.

\section{Strength/Weakness Descriptors}

Verbal attributions of strength and weakness descriptors contrasted. In discussing the female gymnasts, 42 descriptors suggested strength, 
compared with 100 suggesting weaknesses-a ratio of almost 3 to 1 . In the men's competition, there were fewer strength descriptors than in the women's competition (26); however, the narrative that accompanied the use of these descriptors left the audience with little doubt about the power of the male gymnast. He was described as very aggressive, amazing, "going all out from the start to the finish." She was described as the "little girl dancing for gold at the Olympic Games" who was "a little messy on the landing." It is interesting that a total of 67 slow-motion replays were used in the women's competition compared with only 2 in the men's. These segments served to magnify the drama of the event and to build anticipation for the next performance.

\section{Narratives}

As with the 1992 competition, the narrative that accompanied the 1996 Olympic coverage of the gymnastics competition was characterized by conflict and controversy. In attempting to heighten the audience's interest, commentators presented human interest stories on the main U.S. contenders and their European rivals. The injury of Kerry Strugg on the vault was replayed numerous times for the audience, while commentators built up her heroic status as the person who had bravely won the all-around medal for the U.S. team. In reality, at that point, the U.S. women's team had already won the gold medal and there was no need for Strugg to have even vaulted. As the commentators lauded and praised the injured heroine, the camera panned to the crestfallen Russian team as the commentators discussed "the little girls in tears" who "cried these same tears four years ago in Barcelona." The commentators ended the evening with a montage of images from the team competition and with the words "tonight she (Kerry Strugg) was there for Bella (Karoli), for her team, for her country, and for herself;" "there are tears, but I think they are because of joy as well as pain."

The term girl was used numerous times to describe the female gymnasts. This held true for all female gymnasts, regardless of age. Male gymnasts were largely described as men or young men. Although some of the male gymnasts were older than the female gymnasts, equity in this area would help eliminate disparity. There was a focus on the artistic and graceful nature of the gymnastic event as female gymnasts were described as artistic, beautiful, elegant, and passionate. The drama of the comparison was enhanced by the focus on the competition between the Americans and Russians for the team competition. The commentators began the segment by stating "Russia, no longer the specter of evil, but still the threat of beauty and perfection." Thus, the coverage of the women's competition was enhanced by a soap opera or storytelling theme and was "replete with interpersonal conflict as well as personal catastrophe" (Daddario, 1997).

The men's competition was largely ignored by NBC. However, in the brief coverage analyzed, the difficulty of the equipment was mentioned (largely ignored in the women's competition), as was the aggressiveness of 
the participants. In the team compulsory competition, one of the gymnasts was said to have "put on a clinic." The drama of the men's event was enhanced by the focus on a Russian gymnast whose wife was nearly killed the previous summer. Every performance by this gymnast was judged by the commentators as an effort to "win gold for her" (his wife) who is "waiting at home." Thus the framing of the men's competition was done in the context of consequential sensationalism.

\section{SWIMMING AND DIVING}

As with coverage of the 1992 Olympic Games, the swimming and diving coverage was fairly equitable in terms of total time and individual time segments.

\section{Gender Differentials}

Slow-motion replays in the swimming competition (26 for men versus 19 for women) and in the diving competitions (35 for men and 21 for women) were similar. Both ambivalent and sexist comments were used consistently to describe the women swimmers. These included "she's a glamour girl as well as an Olympic champion," "the queen of American swimming" (used to describe Janet Evans), and "look at those long blue fingernails." Both male and female divers were described by words such as beautiful, flawless, and graceful. Male commentators appeared to be far more critical of the female American divers than the male divers when mistakes were made. Comments such as "not the strongest twisting dive" and "a disastrous third round dive" were used to describe the women divers versus "a forceful dive that took a lot of guts to perform" and "very safe, but a little slow" (men) were examples of the different ways that the male commentators described a poor dive.

In the 1992 games, the word girl was used repeatedly to describe the female swimmers. In the 1996 games, this tendency did not continue as the word girl was only used 15 times to describe female swimmers.

\section{Narrative}

As opposed to the blatant sexist comments used to describe the women's events in the 1992 Olympic Games, the narrative used in the 1996 games was quite different. Women swimmers were described as "having a mission" and "very powerful," who "dominated the event." It is conceivable that the success of the women's team in the 1992 games engendered more respect for the 1996 athletes and therefore led to the observed differences between Barcelona and Atlanta. Much was made of Janet Evans' age in comparison with the younger swimmers. The success of this swimmer was also noted by the commentators and her age was discussed at length.

In diving, as with the 1992 competition, the athletes appeared to be covered in a more androgynous manner. Similar adjectives were used to 
describe both competitions, even the appearances of the athletes were discussed equitably. For example, "she and Tom Dolan have no fat" and "his body is immature like the young Chinese girls." Commentators praised the "guts," "skill, and courage" of Mary Ellen Clarke who was in her 30s. Commentators also described the "power of another dream" that had fueled Mary Ellen Clarke's need to compete in the diving competition.

\section{TRACK AND FIELD}

\section{Time Differentials}

Disparity in amount of coverage of the women track and field athletes was still evident in the 1996 Olympic Games. Of the total 4 hours and 48 minutes of track and field coverage analyzed, men were featured for more than twice the amount of time women were featured.

\section{Gender Differentials}

The lack of overtly sexist comments in the track and field competition was a positive change from the blatant sexist manner in which these events were reported in the 1992 games (Higgs \& Weiller, 1994). Gender marking however continued with comments such as "she was the fastest woman in the world" where he "was the world's greatest all around athlete." Male athletes were still lauded for their accomplishment with comments such as "the Joe DiMaggio of long jumpers," "a legend already," and "history being made"; however, women were also recognized for their considerable successes at the games. She was "running very well and very consistently" and "they looked like rockets racing those hurdles" are examples of these types of comments. Overall, there appeared to be greater similarity in the manner in which these athletes were covered.

\section{Narrative}

Depictions of women's personal lives by the commentators were not as overt as in the 1992 competition. Contrasts in presentation of individual biographies of athletes were noted. For example, commentators reported Jackie Joyner Kersee was focusing on her marriage and relationship with her husband, who also happened to be her coach. In a contrasting sketch on Michael Johnson, the focus was purely on his athletic talent. The piece depicted him as a "feared" fighter and the Olympic Games was where "the battle lines would be drawn." After Johnson won his first event, he was highlighted again as a man "whose mission was halfway accomplished," and who was focusing on "making Olympic history" and "thinking "only about gold." For Joyner Kersee, the focus was on her doubts, fears, and family. Such differences in the portrayal of these elite athletes serve to highlight the inequities that still exist in the coverage of men and women in Olympic competition 
and further served to highlight a "storytelling approach" (Daddario, 1997), particularly for the female athletes.

\section{TENNIS, CYCLING (MOUNTAIN BIKING), SOCCER, BASEBALL, AND SOFTBALL}

Relatively little time was devoted to these five sports. The only notable exception was the women's softball competition. Perhaps greater coverage of women's softball was due to the dominance of the American women in this event and the fact that this was the first time this sport had been offered at the Olympic level. The focus of attention during the softball competition was on Dot Richardson as the "oldest player on the team." A biographical sketch showed her as a doctor working with children "and loving it." In the United States versus Puerto Rico game, the commentators called the women's softball team "the other dream team." Comparisons were made to male baseball players like "she's kind of the Cal Ripken of her sport." The baseball competition was very poorly covered, however updates emphasized the "power" of the athletes and how the "1996 games was a record setting Olympics for home runs."

In the women's road race, one of the French cyclists was called "arrogant" because of her "fiery competitiveness and focus of attention." This was compared with an equally dominant male athlete in the mountain biking competition whose competitive fervor was praised and viewed as "so impressive." The male commentators focused on the personal lives of the female cyclists calling one "Mommy medalist" and describing how a woman managed to work out a training schedule "while still being a mom." In describing one of the female cyclist's family arrangements, a male commentator jokingly referred to her family as "hearing about Mom's trip to Atlanta" and how "it's time for the others to help with the dishes."

The drama of the cycling competition was enhanced by the focus on the comparison of women cyclists. In attempting to weave an interesting tale, the commentators talked about how much one cyclist was hated by her peers and that "they would ride the next 64 miles filled with this emotion." Highlights of the women's soccer competition were accompanied by very positive comments such as "the U.S. women are very good" and "she is the best U.S. player and probably the best in the world." Similarly, in the canoeing and rowing competitions, women racers were described as "well disciplined" and "very efficient."

CONCLUSIONS

Commentators have the power to maximize or minimize both men's and women's athletic participation, athletic abilities, and athletic achievements in televised sport events. The importance and relevance of how the mass media chooses to feature athletes aides in shaping popular beliefs, attitudes, and values (Lee, 1992). 
In the past, it has been characteristic of televised sports media to highlight men's and women's sporting events in different ways (Duncan et al., 1990; Harris \& Hills, 1993; Higgs \& Weiller, 1994). Emphasizing these differences reinforces messages that amplify male hegemony not only in sport but in other realms of life (Lambo \& Tucker, 1990). In comparison with the 1992 Olympic Games (Higgs \& Weiller, 1994), findings of the present study suggest the following:

1. Coverage for women increased in two team sports (basketball and volleyball) and in 6 of 11 sports analyzed.

2. Traditional coverage of gymnastics was still evident with disparities in strength/weakness descriptors and an emphasis on human drama, particularly from the female gymnasts.

3. Qualitatively, basketball and volleyball were more evenly presented in the 1996 Olympic Games, with gender marking being the single disparity evident.

4. Swimming and diving continued to be fairly evenly presented; however, both ambivalent and sexist commentary was still employed to describe female swimmers.

5. There was a lack of overtly sexist commentary in track and field as compared with the 1992 Olympic Games; however, some gender differentials in presentation of the narrative was still evident.

6. Overall, narrative analysis revealed a solid focus on the athleticism of the female athlete; however, for both male and female athletes, an intense focus on personal information (background, college attended, playing experience) was noted.

As the pinnacle of amateur performance, the Olympic Games are viewed and respected by millions. The findings of the present study suggest there have been notable changes both quantitatively and qualitatively in the way female athletes were presented in the 1996 Olympic Games, although similarities in the manner of presentation noted in the 1992 Olympic Games (Higgs \& Weiller, 1994) were still evident. Perhaps part of NBC's extraordinary ratings were derived from the focus on the female athlete, both from an athletic and personal perspective. Emphasizing the human drama of the event, utilizing a programming strategy that served to build an emotional identification with the athletes, (Daddario, 1997) and highlighting a specific target audience, may, in part, account for the more positive nature of media presentation of the female athletes. Certainly, findings from this study do suggest there was a definite effort on the part of televised media to present female athletes in a stronger manner.

There is little doubt that the improvements seen in the quality of coverage of the women's events in the 1996 Olympic Games mirrors the advancements made by women in sport since 1992 . The increase in opportunities for women to participate at all levels in sport has led to a new under- 
standing of the role of women in international competition. The success of the women's teams in the 1996 Olympic Games undoubtedly enhanced the reputation and image of women at this level of competition. In addition, as Coakley (1998) suggests, NBC experienced a great rating success when they targeted coverage toward women during these 1996 Games. The improvement in media coverage is encouraging, however, the positive changes that are suggested by this study must be viewed with caution. A limitation of the present study was the limited number of hours analyzed. Although results in the present study may be representative of the total coverage, generalizations to the entire broadcast of the 1996 Olympic Games cannot be made.

Time segments increased in many of the sports analyzed between the 1992 and 1996 Games. However the qualitative analysis of the 1996 Games continues to reveal many disparities, particularly in the coverage of women's sports that traditionally appeal to the media audience (e.g., gymnastics), and perhaps a female audience. It is perhaps this fact that should be most carefully scrutinized. The media is effectively telling us that it is now "OK" to compete in sports, but the image of women in some types of competition remains stereotypically fixed. Despite the "cultural messages" that suggest that sport is an appropriate avenue for women to now compete in, there remains an underlying message that while competing, women should still conform to society's image of what is deemed appropriate. Until the media can totally view women as "athletes" and not "bodies," it is likely that this situation will continue. Old attitudes persist and although the attitudes toward women's sports are changing, the expectations of the behavior and appearance of women athletes remains largely the same.

AUTHORS

Catriona T. Higgs, Ph.D., is a Professor in the Sport Management Program at Slippery Rock University. She has edited or coedited more than 60 presentations and publications on issues ranging from coverage of women in sport by the media, to sociohistorical analyses of the All American Girls' Professional Baseball League, to gender equity issues at the elementary school level. Karen H. Weiller, Ph.D., is an associate professor in the Department of Kinesiology, Health Promotion and Recreation at the University of North Texas. She has presented or copresented more than 50 national, state, or regional presentations and has authored or coauthored more than 20 publications on issues that include coverage of women in sport by the media, to sociohistorical analyses of the All American Girls Professional Baseball League, to gender equity issues at the elementary school level. Scott B. Martin, Ph.D., is an assistant professor in the Department of Kinesiology, Health Promotion and Recreation at the University of North Texas. His research interests include athletes' expectations and attitudes about psychological skills training, preferred coaching behavior, healthy lifestyle interventions, perceived force production, and goal attainment. 


\section{REFERENCES}

Coakley, J. J. (1998). Sport in society: Issues and controversies. Boston: McGraw-Hill.

Daddario, G. (1997). Gendered sports programming: 1992 Summer Olympic coverage and the feminine narrative form. Sociology of Sport Journal, 14, 103-120.

Duncan, M. C., Messner, M. A., Williams, W., \& Jensen, K. (1990). Gender stereotyping in televised sports. Los Angeles: Amateur Athletic Foundation.

Harris, J., \& Hills, L. A. (1993). Telling the story: Narrative in newspaper accounts of a men's collegiate basketball tournament. Research Quarterly for Exercise and Sport, 64, 108-121.

Higgs, C. T., \& Weiller, K. H. (1994). Gender bias and the 1992 Summer Olympic Games: An analysis of television coverage. Journal of Sport and Social Issues, 18, 234-246.

Hillard, D. C. (1984). Media images of male and female professional athletes: An interpretive analysis of magazine articles. Sociology of Sport Journal, 1, 251-262.

Kahn, K. F., \& Goldenberg, E. N. (1991). The media: Obstacle or ally of feminists. ANNALS, AAPSS, 515, 104-113.

Kane, M. J., \& Parks, J. B. (1992). The social construction of gender difference and hierarchy in sport journalism-few new twists on very old themes. Women in Sport and Physical Activity Journal, 1, 49-83.

Lambo, R., \& Tucker, K. W. (1990). Cultures, television and opposition: Rethinking cultural studies. Critical Studies in Mass Communication, 1, 97-116.

Lee, J. (1992). Media portrayals of male and female Olympic athletes: An analysis of newpaper accounts of the 1984 and the 1988 summer games. International Review for Sociology of Sport, 27, 197-222.

Remnich, D. (1996, July). Inside-out Olympics. Newton Massachusetts News Tribune, pp. 26-28.

Shifflet, B., \& Revelle, R. (1994). Gender equity in sports media coverage: A review of the NCAA news. Thousand Oaks, CA: Sage.

Theberge, N. (1991). A content analysis of print media coverage of gender, women and physical activity. Journal of Applied Sport Psychology, 3, 36-48. 